\title{
Study on the Governance Mechanism of Innovation of High-Tech Industrial Cluster in China--Based On KIBS Collaboration
}

\author{
You-Ming Zhu \\ Zhejiang Business College, Hangzhou China, \\ E-mail: zym0573@163.com
}

\begin{abstract}
At present, the industrial cluster is transforming from labor-intensive to knowledge-intensive in China, and the high technology enterprises play an important role in fostering the local economic growth. Based on the resource-based view and collaborative innovation perspective, there formed an interface of collaborative innovation between the high-tech industrial cluster and the embedded knowledge intensive business service, which is the collaboration in four interfaces of strategy, management, business and information, promoting the high technology enterprises' everlasting strong innovation capacity and vitality, and effectively regurgitation-feeding the service industry, realizing the collaborative development of industry.
\end{abstract}

Keywords-Industrial cluster; Governance mechanism; Study

\section{INTRODUCTION}

In the study of industrial cluster theory, increasing attention has been paid to the importance of cluster innovation and cluster innovation behavior for industrial cluster innovation performance. In the study of how the industrial cluster promoting the cluster innovation, the research achievements of domestic and foreign scholars demonstrated the innovation network of the industrial cluster is an important approach for improving the innovation performance of the industrial cluster. However, One of the issues worth to be concerned about is, although a great number of KIBS enterprises exist in and around the high-tech industrial cluster in China, most of the innovation capacity of the high-tech industrial cluster in China is weak, and the collaborative degree of innovation in KIBS enterprises which serve the high technology enterprises is low in particular, so the high technology enterprises cannot use the knowledge spillover from the KIBS enterprises well, infusing the form of the high-tech industrial aggregate and the play of Integrated innovation capability. Therefore, the paper investigates the collaborative innovation mechanism between the high-tech industrial cluster enterprises and KIBS enterprises, in order to effectively enhance the innovation capability of high-tech enterprises and improve the innovation performance of the high-tech industrial cluster.

\section{LITERATURE REVIEW}

Many studies have made comparative analysis of the influential factors in the innovation of high-tech industrial cluster enterprises, and investigated the important role of KIBS enterprises in the innovation process of high - tech industry cluster enterprises.

\section{A. Influencing Factors of Innovation Capability of High-Tech Industrial Cluster Enterprises}

Innovation capability is the most important source of competitive advantage of high-tech industrial cluster, and also is the driving force for the sustainable development of the cluster. And to obtain the knowledge spillovers of the related enterprises or institutions is the fundamental cause of high-tech industrial cluster to improve the innovation capability and obtain competitive advantage. But whether the knowledge spillovers can be transformed into the innovation output of enterprises is highly correlated with the absorptive capacity of enterprises. The Silicon Valley case analysis by foreign scholars reveals that the improvement of Silicon Valley's innovation capability is closely related to the learning ability and absorptive capacity of the enterprises. The dynamic development of cluster depends on its knowledge absorptive capacity, and cluster absorptive capacity depends on the absorptive capacity of each behavior subject for external knowledge source and the interaction between them.[1]In the meantime, due to geographical proximity and organizational proximity in the high tech industry cluster, there will form a strong social network relationship between enterprises and institutions, the social capital embedded in the social network relationship is the main channel of knowledge flow. The existence of this kind of channel promotes the flow and absorption of knowledge in the cluster, and then improves the innovation performance of the enterprise. Due to the blurring of the boundaries between high technology enterprises, and the loose business links, more cooperation with external knowledge infrastructure is needed to promote the transformation of external ideas into effective innovation in the R\&D stage.

According to the above literature, the knowledge absorptive capacity of high-tech industrial cluster enterprises is very important to the innovation activities within the cluster system, and the interaction strength between cluster enterprises and their external knowledge infrastructure has a direct impact on the absorptive capacity of enterprises, and further influence the innovation capability of the enterprise and the innovation performance of the whole industrial cluster.

\section{B. External Activation of Innovation Capability of High Tech Industrial Clusters}

Due to the need of continuous product innovation and process innovation of high-tech industry cluster, high-tech 
enterprises need constantly looking for new sources of knowledge and technology, the success of high-tech enterprises is increasingly dependent on the knowledge and technology obtained from external carrier of knowledge and technology, such as universities, suppliers, advisory services. Knowledge intensive business service (KIBS) are companies and organizations that provide knowledge-based intermediate products or services to society and users, which is rely on the professional knowledge in specialized filed.[2]Due to the KIBS with the characteristics of knowledge innovation function and innovative bridge, there are a large number of this organization forms existing in the high-tech industrial cluster. KIBS enterprises with two characteristics of knowledge production and knowledge transfer, to a certain extent, promote the internal knowledge evolution process of high-tech industrial cluster; become the external knowledge source of cluster enterprises. KIBS enterprises have enhanced the relationship between the cluster enterprises and scientific and technological policy institutions, and built the knowledge bridge between the internal and external knowledge of the customer enterprise, facilitating the integration of internal and external knowledge of cluster enterprises.

According to the above literature, it shows that the KIBS enterprise is an important external activation element of the innovation capability of high-tech industry cluster enterprises. Therefore, to further accelerate the collaborative innovation between high technology enterprises and KIBS enterprises, improving the knowledge absorptive capacity of high technology enterprises has become a necessary approach to improve innovation capacity of high technology enterprises and enhance the performance of cluster innovation.

\section{ANALYSIS ON THE MECHANISM OF COLLABORATIVE INNOVATION BETWEEN HIGH-TECH INDUSTRIAL CLUSTER ENTERPRISES AND KIBS ENTERPRISES}

Due to the fact that the innovation governance of high tech industrial cluster is a kind of governance mechanism based on innovation network, the subject of governance should be the innovation enterprises in the cluster. Therefore, it is necessary to study the motivation and benefits of collaborative innovation in the innovation network between the high technology enterprises and KIBS enterprise.

\section{A. Characteristics of Collaborative Innovation Between High-Tech Enterprises and KIBS Enterprises}

The technological innovation network structure of industrial cluster is formed through the network organization relationship of each innovation subject in the cluster, and high-tech enterprises and KIBS enterprises are the main innovative behavior subjects in this network structure. Universities and research institutions are the source of knowledge innovation, to provide intellectual support, scientific \& technical personnel support and scientific \& technical services for enterprises; intermediary organizations to provide transfer services of information communication and consultation for enterprises, financial services institutions to provide financial support and share the risk of innovation. They collaborate through links arranged in a crisscross pattern, have the innovation information resources flowing and optimizing the allocation within the network, and constitute the technological innovation system of industrial cluster. Industrial cluster innovation network has enhanced the richness of resources in the network through collaborative innovation mechanism, enhanced the strength of network relationship between industrial technology innovation network and social innovation network, established the innovation symbiotic of trust and cooperation relationship, as well as the collaborative innovation atmosphere formed by the relationship among members of the value alliance, promoted the innovation density, scale, intensity and speed of cluster innovation network, and finically improved the innovation performance of cluster.

\section{B. Dynamic Mechanism of Collaborative Innovation Between High Tech Enterprises and KIBS Enterprises}

High-tech enterprises and KIBS companies separate themselves from the original industrial development path and toward collaborative innovation with a powerful dynamic mechanism. As the fundamental driving force for innovation comes from within the system, namely collaboration of subsystems, this dynamic process, in fact, is the process of various elements of the system through the competition mechanism of survival of the fittest, optimizing selection of collocation elements, dynamic selection of the best structural integration, in order to maximize the expansion of the "collaboration surplus" space. High-tech enterprises, KIBS enterprises and system environment together constitute a system and deploy collaboration, and this collaboration enables innovation system to generate overall behavior, enlarging the small local fluctuation of the system, and forming the motivity of innovation, cause the stable transition evolution of the system from the balance to the imbalance, and then to the innovation, to achieve the pursuit and share of innovative revenue with various collaboration party.

\section{Evolution Mode of Collaborative Innovation Between High Tech Enterprises and KIBS Enterprises}

Technology innovation of high-tech industrial cluster enterprises, by enhancing the level of symbiosis and cooperation with KIBS organization which embedded into the cluster, improve the innovation performance of cluster. In the collaboration of high technology enterprises with science and technology services, financial institutions and other KIBS enterprises, through the collaboration mechanism of cluster innovation network, improving the imitation innovation capability and independent innovation capability of the enterprises in the cluster with the network innovation capability which generated from the innovation network. By carrying out scientific research jointly with scientific research institutions, researching market development with management consulting firm, and obtaining information support form services intermediary, as well as the policy and financial support of the government and financial institutions, form an contract mechanism with a clear relationship between rights and responsibilities, with enterprises 
remaining dominant and research institutions as the main alliance of innovation node, with information advisory services and financial institutions for lubrication and with government's policy as support. In the operation of this contract mechanism, through cooperative relations, benefit and risk sharing to promote collaborative innovation of high technology industry cluster innovation network from a single corporate $\mathrm{R} \& \mathrm{D}$ diffusion to the creativity of each node in the innovation network. To shorten the innovation cost and improve cluster innovation capability and speed as much as possible, in order to make enterprise product technology life cycle to meet market demand in time and improve the quick response ability.

\section{INTERFACE FRAMEWORK OF COLLABORATIVE INNOVATION BETWEEN HIGH TECH INDUSTRIAL CLUSTER ENTERPRISES AND KIBS ENTERPRISES}

Through literature review, this paper proposes the interface framework of collaborative innovation between high-tech industrial cluster enterprises and KIBS enterprises.

\section{A. Strategic Collaboration.}

The network relationship in the innovation network structure of industrial cluster is mainly expressed as a contractual relationship, which is mainly reflected in the collaboration of strategic interface. The collaboration of strategic interface establishes a strategic partnership between high-tech enterprises and KIBS enterprises, and highly focuses on business activities of both party and the needs of each other, as well as the integration of respective quality resources, overall planning the resources and outcomes between cross business department and across company projects, collaborative development and evolution, maximizing the overall performance. Due to the efficient collaboration based on the goal of mutual understanding between enterprises. Therefore, based on the goal consistency, establishing a stable strategic partnership can maintain consistency and continuity of the operations and management in both party, on this basis implement resource integration, information sharing, risk and benefit sharing, maximizing the collaboration performance. In addition, the knowledge, skills and resources of high technology enterprises and KIBS enterprises scattered in respective different management department, and effective coordinate and integrate the knowledge and skills of different technologies and resources, depends to an great extend on the establishment of a unified corporate culture, embodied in the management thought and business behavior based on the unified values. Therefore, the collaborative innovation of high technology enterprises and KIBS enterprises, to form a unified values with common recognition among various departments, strategic business unit, managers and employees on both enterprises, to promote the continuous development of both sides in this harmonious and unified enterprise culture atmosphere.

\section{B. Management Collaboration.}

Due to the founder or management personnel of the high technology enterprises mostly is engineering technical personnel who came out from the University and research institute, they understand the latest trends in technology development and quick response to potential new technologies and possible applications, but generally lack of management experience. Therefore, there are a lot of collaboration in management interface for the innovation of high technology enterprises and KIBS enterprises. High-tech enterprises can take full advantage of the power of KIBS enterprises to provide feasible suggestions for their own management decisions, reconstruction or transformation the management process of enterprise. The two sides need to be adjusted organizational structure, change Partnership, negotiate cooperation rules and improve innovation performance on the established cooperation platform according to market changes, and effective monitoring the various stages of collaborative innovation.

\section{Business Collaboration.}

The collaborative innovation of high-tech enterprises and KIBS enterprises is the collaborative operations that the technical circulation field enters into the production field. Specifically reflected in the universities, research institutes and other non commercial public education resources compensable transfer the scientific and technological achievements to the enterprise, help the enterprises to form independent knowledge products; the management consulting company provide management consulting and problem solutions for high technology enterprises with their own management knowledge dissemination institutions, improve the management level of enterprises; professional services organizations in the field of accounting and legal to meet the business demands of high technology enterprises, using the proprietary knowledge of the administrative system and social public affairs to help high-tech enterprises communicate with complex social systems. The engineering technology, information technology and other fields of professional service organizations provide software and other knowledge tools for high technology enterprises with their own proprietary and sophisticated technology. Product development is the life of high technology enterprises. But due to the limit of economic strength, its R\&D strength has been greatly restricted. Therefore, through the government funding, universities and research institutions bearing, the collaboration of common technology platform which meet the needs of independent innovation of high-tech industrial cluster become an important path to promote the independent innovation of high technology enterprises. The high technology enterprises take advantage of the technology collaboration with the common technology platform of the cluster innovation network, share technology development resources, reduce the cost of product development and improve product performance.

\section{Information Collaboration.}

The collaborative innovation of strategy, management and business interface of high technology enterprises and 
KIBS enterprises must be implemented through information platform, connection, exchanged and processing of information in the information platform. Therefore, there are a large number of collaborations in the information interface of high-tech enterprises and KIBS enterprises. High technology enterprises and KIBS enterprises use the modern information technology, such as Internet, database and so on, optimization, scheduling and management of various behaviors of strategy, management and business interface; the two sides are connected with database (the database includes the database of high technology enterprises, KIBS enterprises and other network of innovation participating parties et.al) through computer network, perform data transfer and information exchange.

\section{REFERENCES}

[1] Wei Jiang, Zhu Haiyan, "An Empirical Study on the Networked Innovation Process and Performance within Industrial Clusters", Science and China Youth Technology, vol.3, no.9, pp.23-28, 2007.

[2] Wei Jiang, Mark Boden, Knowledge Intensive Business Service and Innovation, Beijing: Science Press, March.2004. 